\title{
Late Intraluminal Stent Application in Strictures due to Corrosive Esophagitis: Our Preliminary Experiences
}

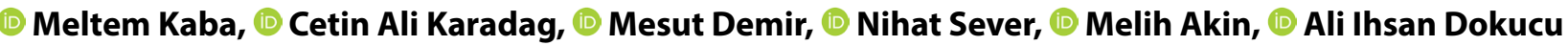 \\ Department of Pediatric Surgery, Sisli Hamidiye Etfal Training and Research Hospital, Istanbul, Turkey
}

\begin{abstract}
Objectives: Household chemicals result in corrosive esophageal burns in the developing third world countries, and most of them cause esophageal strictures. There is no standard treatment for esophageal strictures. Here, we present our preliminary experience with intraluminal esophageal stents for stricture treatment.

Methods: The files of the patients who had stenosis due to corrosive esophagitis in our clinic were evaluated retrospectively. Stricture lengths were between 30 and $130 \mathrm{~mm}$. Stents were self-expandable, made of nitinol alloy that was covered with silicone, and they were cylindrical in shape with a conical tip. The lengths varied between 60 and $170 \mathrm{~mm}$ and the diameters were between 10-20 mm. The stent application was made under general anaesthesia.

Results: There were seven patients (four girls and three boys). After stent application, all patients experienced constant or temporary pain, vomiting, and difficulty in swallowing. Bleeding occurred in one patient. Sudden death occurred in one patient, probably as a complication of chest infection. All stents had to be removed in mean 38 days because of embedding of the stent, development of granulation tissue and intolerance.

Conclusion: More research is needed to determine the type, length and diameter of the stent, the timing and the duration of the application, the length and level of the stricture suitable for stent application and medications during treatment.

Keywords: Corrosive esophagitis; esophageal stricture; stent; nitinol.

Please cite this article as "Kaba M, Karadağ ÇA, Demir M, Sever N, Akın M, Dokucu Al. Late Intraluminal Stent Application in Strictures due to Corrosive Esophagitis: Our Preliminary Experiences. Med Bull Sisli Etfal Hosp 2020;54(2):176-180".
\end{abstract}

U nconscious use of sophisticated household chemicals in underdeveloped countries causes esophageal burns, especially in pediatric age groups. While the followup and treatment of this clinical entity bring about a serious workload in the related health institutions, on the other hand, it causes psycho-social traumas in children and their families. Especially in deep burns, the gold standard treatment of esophageal strictures, which occurs with the burn healing process, has not been found yet.

Today, in stenoses that arises from corrosive esophagitis, esophageal replacements are performed when the re- sponse to dilatation cannot be obtained, but these procedures also carry high risks of morbidity and mortality. ${ }^{[1]}$ Although esophageal stents are widely used in adults with different indications, experiences in the child age group are limited. ${ }^{[2,3]}$ In our study, our first experiences on stent applications that we use in esophageal strictures are presented.

\section{Methods}

The files of patients who developed stenosis due to corrosive esophagitis and who had undergone stent treatment in our clinic were evaluated retrospectively. These cases 
constituted patients who underwent stent therapy because we could not have a response to dilatation therapy and the patients did not accept esophageal replacement therapy. According to the dilatation program we are performing in the clinic, the dilatation which is generally performed once a week under general anesthesia is maintained at two, three and four-week intervals depending on the response obtained. Patients who could not be fed orally for more than a week after the six-month dilatation program were considered as non-responders to this therapy. Stents were applied to these patients who needed frequent dilatations because they did not respond to treatment and still complained of swallowing problems.

The stents we used were silicone coated on the cylindrical nitinol alloy structure, with a funnel-shaped upper end. They were self-expanding and removable when inserted, and could be produced in a custom size and diameter (Nanjing Microinvasive Co. Ltd. Nanjing, P.R.C.) (Fig. 1). Stent lengths were calculated, starting from $2 \mathrm{~cm}$ proximal and extending $2 \mathrm{~cm}$ distal to the stenosis. The stents applied were $10-20 \mathrm{~mm}$ in diameter and $60-170 \mathrm{~mm}$ in length. After dilatation was performed, the largest stents we could insert into the esophagus were selected. The stents were placed under general anesthesia with the aid of the $18 \mathrm{~F}$ applicator and radiological imaging. The patients were followed up with weekly chest radiograms obtained against the possibility of stent slipping (Fig. 2b). To protect patients from reflux esophagitis that may be triggered due to stent in situ, a proton pump inhibitor was given at doses of 15 $\mathrm{mg} /$ day and sodium alginate (Gaviscon ${ }^{\circledast}$ liquid) $4 \times 5 \mathrm{ml} /$ day. The stents placed in the stenotic area left in situ for at least six weeks. ${ }^{[4-6]}$

\section{Results}

Between January and November 2005, seven patients, including four girls, and three boys, aged between one and 13 years, underwent stenting procedures (Table 1). The length of the stenotic segment of our cases varied between 30 and $130 \mathrm{~mm}$. All patients had complaints of pain, vomiting, and difficulty swallowing after stenting. These complaints were most intense within the first 48 hours, and as the dwelling time of the stent increased, the complaints decreased. To control pain, parenteral metamizole sodium and rectal paracetamol preparations were used, but the mostly adequate therapeutic response was not obtained.

Patients whose stents were placed more proximally (Table 1 ; patients 2,4 and 7) complained more frequently of gagging, difficulty in swallowing and pain. Only in the case of stenosis in the distal esophagus where shorter stents (Table 1 ; patient 6 ) were used, pain and stinging in the throat were

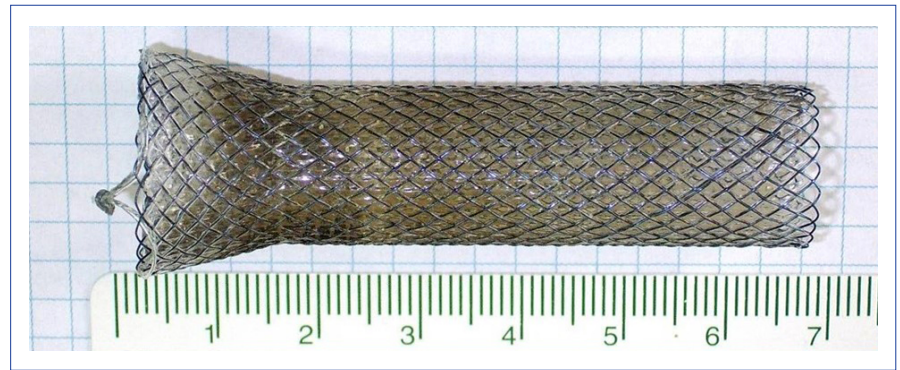

Figure 1. Nitinol esophageal stent.

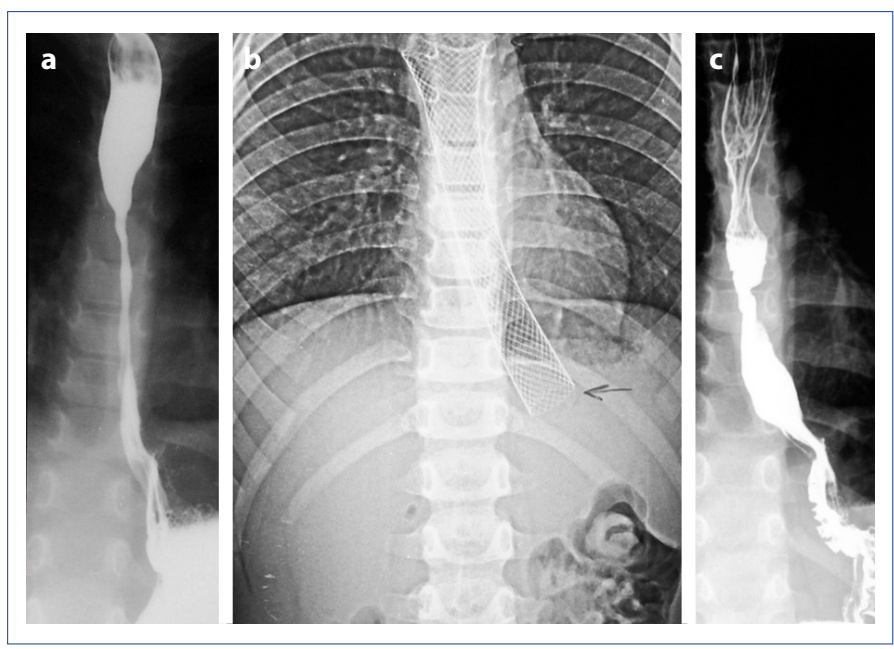

Figure 2. (a) Pre-stenting esophageal passage graphy of the patient (b) control graphy performed of the patient with the stent, (c) esophageal passage graphy performed after removal of the stent.

relatively less frequent, and these complaints persisted with decreasing frequency. Patients who were able to tolerate swallowing or feeding from gastrostomy tube were discharged (mean 6 days, median 2 days) and followed up on an outpatient basis.

In one patient, the lesion that could explain the hematemesis seen on the night of stenting and the next day was not found in the endoscopic examination performed (Table 1; patient 1). The stent was left in place and the bleeding did not recur in the following days.

A patient who was treated for pneumonia twice during the pre-stent period was hospitalized in the pediatric clinic due to recurrent episodes of pneumonia occurring after the stent was inserted. Although the lungs of the patient could be ventilated normally through an endotracheal tube, this case that was hospitalized in our clinic for close follow-up did not respond to resuscitation and died on the 16th day of therapy due to sudden-onset of respiratory distress, cyanosis, and subsequent development of cardiopulmonary arrest (Table 1; patient 7).

On the radiograms obtained, it was seen that the stent was patent and in place. Since autopsy was not performed, it 
Table 1. Characteristic features of the patients

\begin{tabular}{|c|c|c|c|c|c|c|c|}
\hline Patient no. & 1 & 2 & 3 & 4 & 5 & 6 & 7 \\
\hline Age & 9 & 2 & 6 & 13 & 6 & 1 & 5 \\
\hline Corrosive substance & Alkaline & Alkaline & Alkaline & Alkaline & Alkaline & Alkaline & Alkaline \\
\hline ingested Gastrostomy & Yes & Yes & No & Yes & Yes & No & Yes \\
\hline $\begin{array}{l}\text { Stenotic area (distance } \\
\text { from the incisors) }\end{array}$ & $\begin{array}{c}13 \mathrm{~cm} \text { stenosis } \\
\text { at a distance } \\
\text { of } 22 \mathrm{~cm}\end{array}$ & $\begin{array}{c}4 \mathrm{~cm} \text { stenosis } \\
\text { at a distance } \\
\text { of } 10 \mathrm{~cm}\end{array}$ & $\begin{array}{l}5 \mathrm{~cm} \text { stenosis } \\
\text { at a distance } \\
\text { of } 10 \mathrm{~cm}\end{array}$ & $\begin{array}{c}6 \mathrm{~cm} \text { stenosis } \\
\text { at a distance } \\
\text { of } 16 \mathrm{~cm}\end{array}$ & $\begin{array}{c}6 \mathrm{~cm} \text { stenosis } \\
\text { at a distance } \\
\text { of } 19 \mathrm{~cm}\end{array}$ & $\begin{array}{l}1 \mathrm{~cm} \text { circumferential } \\
\text { stenosis at a distance } \\
\text { of } 13 \mathrm{~cm} \text { and } \\
3 \mathrm{~cm} \text { stenosis at } \\
\text { a distance } \\
\text { of } 20 \mathrm{~cm}\end{array}$ & $\begin{array}{l}3 \mathrm{~cm} \text { stenosis at } \\
\text { a distance of } \\
16 \mathrm{~cm} \text {, and } 2 \mathrm{~cm} \\
\text { at stenosis } \\
\text { a distance } \\
\text { of } 2 \mathrm{~cm}\end{array}$ \\
\hline $\begin{array}{l}\text { Diameter and length of } \\
\text { the stent }(\mathrm{mm})\end{array}$ & $16 \times 170$ & $16 \times 60$ & $20 \times 120$ & $20 \times 100$ & $16 \times 100$ & $16 \times 60$ & $16 \times 80$ \\
\hline Sent dwelling time (days) & 60 & 31 & 43 & 37 & 30 & 30 & 16 \\
\hline
\end{tabular}

was not shown whether the stent had a direct effect on the death of the patient.

Relocation of the stent was performed because the stent slid upwards in one and downwards in another patient. One patient had never been able to switch to oral feeding after the stent was inserted. Since the patient had not a gastrostomy tube, the case could not be discharged and was hospitalized until the stent was removed and feeding could be achieved with the aid of a nasogastric tube advanced through the stent.

Initially, at least six weeks of stent dwelling time was planned; however, stents were removed approximately 38 days after their insertion because of tolerance problems, such as pain, inability to vomit, and detection of intense granulation at the upper end of the stent and buried stent during endoscopic controls performed at the end of the first month. There was no problem in removing the stent. The patients were followed up for 12 and 18 months (average 14 months) after the stent was removed. After removing the stents, swallowing problems continued in all patients, and accordingly, the dilatation program was maintained. However, during esophagoscopy performed previously, patency of the lumen could hardly be observed throughout the entire length of the esophagus. After stenting although small in size, a lumen was formed through which dilator guide or the initial dilator could be advanced. In patients who received dilatation for an average of 28 days before stenting, the frequency of dilatation increased, when it had to be performed at intervals of 25 days.

\section{Discussion}

In esophageal strictures that develop after corrosive substance intake, patients are monitored with repeated dilatations, and alternative treatments are sought when the dilatations cannot be performed at longer intervals. Esophagus-sparing methods, such as dilatation and stent treatment, are preferred more frequently in the pediatric age group because these treatment approaches comply with the well-known motto: "The patient's own esophagus is the best esophagus."

Self-expanding nitinol stents have been used for a long time in the palliative treatment of malignant diseases in adults. Apart from malignant diseases of the esophagus, it has been reported to be used for the treatment of malignant or benign stenosis of various regions, such as the trachea, intestinal system and urethra. ${ }^{[7,8]}$ Nitinol is an alloy made of nickel and titanium and is sensitive to temperature changes.

While it is flexible and soft in low temperatures $\left(0-4{ }^{\circ} \mathrm{C}\right)$, it becomes harder at body temperature. When nitinol stent is applied, it reaches its diameter set in the esophagus after 24 hours. The tension force exerted on the esophageal wall during the opening of the stent is equal on all sides. Esophageal enlargement in the stricture area is slower and softer compared to balloon dilatation..$^{[9]}$ These stents, which are made of nitinol and gained a cylindrical structure with various knitting shapes, are further expanded with body temperature in the lumens of the organs where they are placed, preventing their displacement. They expand in situ, and dilate the stenotic segment to its normal diameter. Thanks to their unique feature, they seem to be an ideal tool in the management of esophageal stenoses; however, we observed that in our cases, occasionally stents caused pressure sores in the esophagus and were buried into the tissue.

Although buried stents may not cause a disadvantage in the palliative treatment of tumors, the stent can be easily removed from this area after providing the expected ex- 
pansion, which is a desired feature of the stents in cases with benign stenosis. While the inner surface of the stents we use is covered with silicone with the intention to prevent the burial of the stent, the outer surface is not covered to prevent the stent from slipping by adhering to the lumen of the esophagus more strongly. Given that only two of our patients had stent slippage in 266 stent days, which would require repositioning, shows that this goal was achieved. An important element that prevents slipping is the pressure of the stent on the lumen wall, and thus the diameter of the stent. We experienced a limited number of slipping problems, which may have been related to our practice of using large stents.

A string is attached circumferentially around the upper part of the stent so that it can be easily removed. When it is pulled, the diameter of the nitinol stent begins to decrease towards its distal end starting from this part. However, since the upper part of the stents where this string is attached is deprived of silicone coating, we observed the formation of dense granulation tissue on the upper part of the stent, which also started to be buried. While the length of the stents used was determined based on the length of the stenotic area of the esophagus, we could not find a specific criterion for the intraluminal diameters of the stents. Since the anatomy and physiology resource books do not have information about the length and diameter of the child's esophagus and considering that the stents are flexible to fit the width of the esophagus, use of stents with a diameter of $20 \mathrm{~mm}$, and $16 \mathrm{~mm}$ was planned for patients over, and below seven years of age, respectively. However, in the following days, we observed that the pain and vomiting complaints were highly frequent in patients due to implantation of stents with a larger diameter. Besides, the formation of granulation tissue, and stent burial occurring at the upper end of these stents by causing more pressure wounds made us abandon the use of $20 \mathrm{~mm}$ - diameter stents. It has also been reported that such burial and granulation tissue formation may cause secondary strictures. ${ }^{[10]}$ Despite the opinion that long term stent treatment between 6-12 months may be beneficial in preventing stenosis in the strictures developing after corrosive esophagitis, in animal studies, compared with stentless management of esophageal strictures, two weeks of stenting less frequently led to stenosis, and stenosis disappeared within three weeks of stenting.

There are also studies that suggest that the stent dwelling time should not exceed four weeks because of the potential complication of the buried stent. In our study, we chose stenting for six weeks which indicated that mucosal reepithelialization was completed ${ }^{[11]}$ However, despite this result, we could not achieve successful results in our patients in whom we applied stents for the short term. We did not have any patient whose dilatation requirement disappeared as a result of stent application. Requirement for dilatation did not change significantly in all of our patients, except for one patient whose dilatation requirement decreased compared to the pre-stent period. However, in endoscopic examinations and barium esophagography (Fig. $2 \mathrm{a}, \mathrm{c})$, the lumens were wider than before stenting, and dilatations could be started with larger dilators. We think that the higher frequency of dilatation after stenting may be due to the closer follow-up and control of these patients on time.

There is no accepted protocol for stent applications in corrosive esophagitis. In our article, our first experiences and problems with nitinol stents, which we think are promising in the treatment of esophageal stenoses due to corrosive esophagitis, are presented. The short-term stenting method we used in esophageal stenosis developed after corrosive esophagitis did not provide significant clinical improvement in swallowing problems. Type, length, diameter, and dwelling time of the stents, the timing of stent implantation after the esophageal long after the incident of corrosive esophageal burn, length and localization of strictures suitable for stenting, and concomitant drug treatment have not been standardized yet. More research is needed to solve this equation with many unknowns.

\section{Disclosures}

Ethics Committee Approval: Retrospective study.

Peer-review: Externally peer-reviewed.

Conflict of Interest: None declared.

Authorship Contributions: Concept - M.K., Ç.A.K.; Design M.D.; Supervision - M.K., Ç.A.K.; Materials - M.K., M.A.; Data collection \&/or processing - N.S.; Analysis and/or interpretation M.K., A.I.D.; Literature search - M.K., Ç.A.K.; Writing - M.K., Ç.A.K.; Critical re- view - A.I.D.

\section{References}

1. Spitz L. Esophageal Replacement. In: Grosfeld J, O'Neill, Coran A Fonkalsrud E. Pediatric Surgery. 6th ed. Philadelphia: Mosby Elsevier; 2006. p. 1093-106. [CrossRef]

2. Lee $\mathrm{SH}$. The role of oesophageal stenting in the non-surgical management of oesophageal strictures. Br J Radiol. 2001;74(886):891900. [CrossRef]

3. Zhang C, Yu JM, Fan GP, Shi CR, Yu SY, Wang HP, Ge L, Zhong WX. The use of a retrievable self-expanding stent in treating childhood benign esophageal strictures. J Pediatr Surg 2005;40:501-4.

4. Cheng YS, Li MH, Chen WX, Zhuang QX, Chen NW, Shang KZ. Follow-up evaluation for benign stricture of upper gastrointestinal tract with stent insertion. World J Gastroenterol 2003;9:2609-11.

5. Maetani I, Ukita T, Inone H, Yoshida M, Igarashi Y, Sakai Y. Knitted 
nitinol stent insertion for various intestinal stenoses with a modified delivery system. Gastrointest Endosc 2001;54:364-7. [CrossRef]

6. Reyes HM, Hill JL. Modification of the experimental stent technique for esophageal burns. J Surg Res 1976;20:65-70. [CrossRef]

7. Peppo FD, Rivosecchi M, Federici G, Matarazzo E, Ponticelli A, Schingo $P$, et al. Conservative treatment of corrosive esophageal strictures: A comparative study of endoscopic dilatations and esophageal stenting. Pediatr Surg Int 1993;8:2-7. [CrossRef]

8. Shin JH, Song HY, Ko GY, Shim TS, Kim SW, Cho YK, et al. Treatment of tracheobronchial obstruction with a polytetrafluoroethylenecovered retrievable expandable nitinol stent. J Vasc Interv Radiol
2006;17:657-63. [CrossRef]

9. Cwikiel W, Willén R, Stridbeck H, Lillo-Gil R, von Holstein CS. Selfexpanding stent in the treatment of benign esophageal strictures: experimental study in pigs and presentation of clinical cases. Radiology 1993;187:667-71. [CrossRef]

10. Mutaf O. Treatment of corrosive esophageal strictures by longterm stenting. J Pediatr Surg 1996;31:681-5. [CrossRef]

11. Millar AJW, Numanoglu A, Rode H. Caustic strictures of the esophagus. In: Grosfeld JL,O'Neill JA, Fonkalsrud EW, Coran AG, editors. Pediatric Surgery. 6th ed. Philadelphia: Mosby Elsevier; 2006. p. 1082-92. [CrossRef] 